\title{
HAZARDS IDENTIFICATION AND RISK ANALYSIS IN POST PRINTING LABORATORIES OF STATE POLYTECHNIC OF CREATIVE MEDIA
}

\section{IDENTIFIKASI BAHAYA DAN PENILAIAN RESIKO DI LABORATORIUM PASCA CETAK POLITEKNIK NEGERI MEDIA KREATIF}

\author{
Elvianaa*, Antinah Latifb, Dafa Algiasa Yudistira \\ Teknik Grafika, Politeknik Negeri Media Kreatif, Indonesia \\ *Email: elviana@polimedia.ac.id
}

\begin{abstract}
Every workplace and activity has potential hazards and risks that can cause work accidents, as well as laboratories in the educational environment. Post-printing laboratories have the potential to have dangers and risks because of the sources of hazards and work activities by both students and instructur and operators. The aims of this paper is to determine the potential hazards and risks; know risk assessment using HIRA method and control of hazards and risks. Data collection techniques used in this paper are observation, interviews and literature study. Based on the results of this paper, the potential hazard with the highest value is found in the type of activity operating a perfect binding machine with a total of 8 hazards. The risk assessment obtained a low risk level of 50\%, extreme $30 \%$, moderate $15 \%$ and high 5\%. This extreme level of risk is influenced by the use of chemicals in the perfect binding process. Some controls have been implemented but some are not functioning properly. Suggested controls are engineering and administrative control design.
\end{abstract}

Keywords-Hazard, Risk, HIRA method, Post printing

\begin{abstract}
Abstrak- Setiap tempat kerja dan aktivitas memiliki potensi bahaya dan risiko yang dapat menyebabkan kecelakaan kerja, begitu juga dengan Laboratorium yang ada di lingkungan Pendidikan. Laboratorium pasca cetak berpotensi memiliki bahaya dan risiko karena adanya sumber bahaya dan aktivitas kerja baik oleh mahasiswa maupun para PLP dan operator. Tujuan dari penulisan ini adalah untuk mengetahui potensi bahaya dan risiko; mengetahui penilaian risiko dengan metode HIRA dan pengendalian bahaya dan risiko. Teknik pengumpulan data yang digunakan dalam penulisan ini adalah observasi, wawancara dan studi pustaka. Berdasarkan hasil penulisan ini bahwa potensi bahaya dengan nilai tertinggi terdapat pada jenis
\end{abstract}


kegiatan mengoperasikan mesin perfect binding dengan total 8 bahaya. Penilaian risiko didapatkan level risiko rendah sebesar 50\%, ekstrim sebesar 30\%, sedang sebesar $15 \%$ dan tinggi sebesar 5\%. Level risiko ekstrim ini dipengaruhi oleh penggunaan bahan kimia di proses perfect binding. Beberapa pengendalian sudah diterapkan namun ada yang tidak berfungsi sebagaimana mestinya. Pengendalian yang disarankan adalah rancangan Teknik dan administrasi.

Kata Kunci-Bahaya, Risiko, Metode HIRA, Pascacetak

\section{PENDAHULUAN}

Laboratorium pendidikan menurut Peraturan Menteri Pendayagunaan Aparatur dan Reformasi Birokrasi Nomor 3 Tahun 2010 adalah unit penunjang akademik pada lembaga pendidikan, berupa ruangan tertutup dan terbuka, bersifat permanen atau bergerak, dikelola secara sistematis untuk kegiatan pengujian, kalibrasi, dan/atau produksi dalam skala terbatas, dengan menggunakan peralatan dan bahan berdasarkan keilmuan tertentu. Dosen, laboran, teknisi laboratorium, mahasiswa atau siapa pun yang berkegiatan di sana wajib dijaga keselamatan dan kesehatannya.

Setiap tempat kerja dan aktivitas memiliki potensi bahaya dan risiko yang dapat menyebabkan kecelakaan kerja. Bekerja dan melakukan aktivitas di laboratorium pun tidak akan lepas dari kemungkinan terjadinya kecelakaan kerja. Besarnya potensi kecelakaan kerja tergantung dari jenis produksi, teknologi yang dipakai, bahan yang digunakan, tata ruang dan lingkungan serta kualitas manajemen dan tenaga pelaksana (Ramadhani, 2017).

Effendi et al. (2018) menyatakan bahwa ada dua penyebab terjadinya kecelakaan kerja yaitu terjadi karena penyebab langsung (kondisi tidak aman dan tindakan tidak aman) dan penyebab dasar (lemahnya manajemen dan pengendalian, kurang sarana prasarana, kurang sumber daya, kurang komitmen, dan lain-lain). Untuk mengantisipasi kecelakaan kerja perlu dilakukan manajemen risiko. Langkah pertama dalam proses manajemen risiko adalah dengan melakukan identifikasi bahaya dan risiko di tempat kerja (Roehan et al. 2014). Identifikasi bahaya dan resiko adalah sebuah identifikasi yang mengenai aspek dampak lingkungan operasional perusahaan terhadap alam dan penduduk 
sekitar di wilayah perusahaan menyangkut beberapa elemen seperti tanah, air, udara, sumber daya energi serta sumber daya alam lainnya termasuk aspek Flora dan Fauna di lingkungan perusahaan (Ariani, 2016). Identifikasi bahaya merupakan suatu proses yang dapat dilakukan untuk mengenali seluruh situasi atau kejadian yang berpotensi sebagai penyebab terjadinya kecelakaan dan penyakit akibat kerja yang mungkin timbul di tempat kerja. (Tarwaka, 2008). Identifikasi bahaya dan resiko menjadi langkah awal perencanaan terkait penerapan K3 di lingkungan tempat kerja.

Politeknik Negeri Media Kreatif merupakan instansi pendidikan yang salah satu misinya adalah menciptakan program pendidikan yang berbasis produksi dan kewirausahaan. Pascacetak merupakan salah satu laboratorium untuk simulasi produksi di lingkungan Pendidikan. Aktivitas di laboratorium tersebut berkaitan dengan alat, mesin, dan bahan kimia yang memiliki potensi bahaya dan risiko. Berdasarkan uraian diatas, penulis tertarik untuk melakukan identifikasi bahaya dan risiko di Laboratorium Pasca Cetak Politeknik Negeri Media Kreatif. Dengan dilakukannya identifikasi bahaya dan risiko diharapkan menjadi dasar dalam penerapan K3 di tempat tersebut.

\section{METODE PENELITIAN}

Metode yang digunakan dalam penelitian ini sebagai berikut :

\section{Observasi}

Metode ini dilakukan dengan cara mengamati dan mempelajari berbagai macam kegiatan, peralatan dan mesin yang digunakan, lingkungan kerja, serta bahan yang digunakan. Selain itu penulis menggunakan form Hazard Identification and Risk Assesment (HIRA) dalam menentukan potensi bahasa dan risiko yang ada di Laboratorium Pascacetak Polimedia.

2. Studi Pustaka

Metode ini digunakan untuk memperkuat hasil penelitian karena harus mempelajari buku dan artikel yang digunakan sebagai landasan untuk teoriteori yang digunakan dalam penulisan ini.

\section{Wawancara}

Wawancara dilakukan untuk memperdalam temuan yang sebelumnya dilakukan serta memastikan validitas temuan tersebut. Wawancara dilakukan penulis kepada PLP dan teknisi di laboratorium pasca cetak.

\section{HASIL DAN PEMBAHASAN}

Identifikasi Bahaya dan Risiko di

Laboratorium Pascacetak Politeknik

Negeri Media Kreatif 
Vol.8, No. 2, Oktober 2021, hal. 113-120

Submitted: 28 September 2021 Revised: 6 Oktober 2021

Accepted: 18 Oktober 2021

Identifikasi bahaya dan risiko diidentifikasi melalui observasi dan diyakinkan dengan wawancara. Dalam mengidentifikasi bahaya dan risiko di laboratorium, perlu diketahui beberapa hal yaitu kegiatan yang dilakukan, mesin yang digunakan, kondisi lingkungan kerja, dan bahan yang digunakan. Setelah data diperoleh kemudian dilakukan pengelompokkan bahaya dan risiko berdasarkan jenis bahaya. Menurut Khurniawan et al. (2020), bahaya dibagi menjadi bahaya yang berkaitan dengan kesehatan kerja dan bahaya yang berkaitan dengan keselamatan kerja berdasarkan bahaya keselamatan kerja berdasarkan bahaya keselamatan kerja.

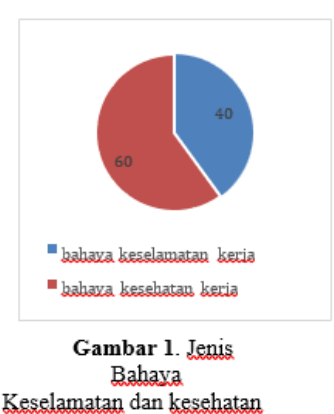

Keselamatan dan kesehatan

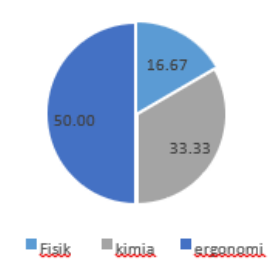

Gambar 2. Persentase ienis bahaya

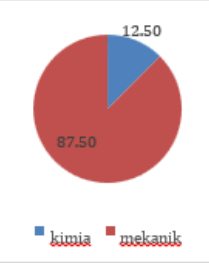

Gambar 3. Persentase ienis bahava berdasarkan bahaxa kesehatan keria

Cabel 1. Identifikasi dan jenis bahava di Laboratorium Pascacetak Polimedia

\begin{tabular}{|c|c|c|c|}
\hline Kegiatan & $\begin{array}{l}\text { Petensi } \\
\text { bahava }\end{array}$ & $\begin{array}{c}\text { Bahaya Kesehatan } \\
\text { Keria/Keselamatan Keria }\end{array}$ & $\begin{array}{l}\text { Jenis } \\
\text { bahava }\end{array}$ \\
\hline \multirow[t]{3}{*}{ Memotong } & $\begin{array}{l}\text { Tangan tersayat } \\
\text { kertas }\end{array}$ & Bahava keselamatan keria & Mebanik \\
\hline & Tari terpetong & Bahava keselamatan keria & Mekanik \\
\hline & Kelelahan & Bahava kesehatan keria & Ergonomi \\
\hline \multirow[t]{3}{*}{ Melipat= } & $\begin{array}{l}\text { Material tersangkut } \\
\text { mesin }\end{array}$ & & \\
\hline & lipat & Bahava kesehatan keria & Ergonomi \\
\hline & Kelelahan & Bahava kesehatan keria & Ergonomi \\
\hline \multirow[t]{2}{*}{ Mengomplit } & $\begin{array}{l}\text { Kellelahan } \\
\text { Bahan setakan } \\
\text { terselin }\end{array}$ & Bahava kesehatan keria & Ergonomi \\
\hline & $\begin{array}{l}\text { karena penerangan } \\
\text { kurang }\end{array}$ & Bahava kesehatan keria & Fisilo \\
\hline \multirow[t]{3}{*}{ Menxisir } & $\begin{array}{l}\text { Tangan tersayat } \\
\text { kertas }\end{array}$ & Bahava Keselamatan Keria & Mekanik \\
\hline & Tari terpetong & Bahaxa Keselamatan Kerja & Mekanik \\
\hline & Kelelahan & Bahava kesehatan keria & Ergonomi \\
\hline Laminating & Tangan teriepit roll & Bahava Kesselamatan Kerja & Melanik \\
\hline \multicolumn{4}{|l|}{ Perfect Bimaing } \\
\hline & $\begin{array}{l}\text { Tangan teriepit saat } \\
\text { kuras }\end{array}$ & Bahava keselamatan keria & Mekanik \\
\hline & $\begin{array}{l}\text { Tangan terkena lem } \\
\text { panas } \\
\text { fem tumpah karena } \\
\text { tidak }\end{array}$ & Bahaxa kesehatan keria & Fisilo \\
\hline & $\begin{array}{l}\text { ada penuimpanan } \\
\text { chusus. }\end{array}$ & Bahava kesehatan keria & Ergonomi \\
\hline & $\begin{array}{l}\text { Pusing terhirup } \\
\text { bahan kimia }\end{array}$ & Bahava kesehatan keria & Kimia \\
\hline & Dermatitis bullit & Bahava kesehatan keria & Kimia \\
\hline & $\begin{array}{l}\text { Kerusakan saraf } \\
\text { pusat }\end{array}$ & Bahava kesehatan keria & Kimia \\
\hline & Kanker pary & Bahava kesehatan keria & Kimia \\
\hline & Kebalkaran & Bahava keselamatan keria & Kimia \\
\hline Pengemasan & Tari tersavat cutter & Bahava keselamatan keria & Melanik \\
\hline
\end{tabular}

Beberapa pekerjaan di pasca cetak banyak dilakukan dengan posisi berdiri, posisi duduk, dan gerakan yang repetitif. Sedangkan pada bahaya kesehatan kerja, bahaya mekanik menyumbang persentase sebesar $87,50 \%$ hal ini disebabkan dalam aktivitas pasca cetak juga berhubungan dengan mesin yang menimbulkan panas, mesin potong dan mesin yang menggunakan roll. 
Berdasarkan identifikasi tersebut diketahui bahwa pada proses perfect binding menyumbang potensi bahaya paling banyak sebesar 8 bahaya. Pada proses ini, banyak menggunakan bahan kimia yang dapat menimbulkan efek jangka panjang bila tidak tertangani dengan baik. Bahan kimia yang digunakan pada proses pasca cetak adalah. lem dingin dan lem panas (Madjid dan Nurjalih, 2013) yang keduanya mengandung poly vinyl acetate. Berdasakan Lembar Data Keselamatan Bahan (LDKB), poly vinyl acetate bersifat karsinogenik, menyebabkan edema di kulit, mudah terbakar dan menyebabkan ledakan yang dampaknya signifikan. Selain lem dingin dan panas, pada proses ini juga menggunakan tinner. Tenaga laboran bekerja selama 8 jam. Pekerjaan pasca cetak di Laboratorium Pasca Cetak di Polimedia tidak sebanyak pekerjaan di percetakan luar pada umumnya. Tetapi, tenaga laboran umumnya berada di ruangan tersebut selama 8 jam sehari (ada pekerjaan atau tidak ada pekerjaan).

Penggunaan Tabel HIRA dalam Penilaian Risiko di Laboratorium Pasca Cetak Politeknik Negeri Media Kreatif

Penilaian risiko dilakukan dengan mengalikan nilai frekuensi dan keparahan. Hasil perkalian tersebut disesuaikan dengan matriks penilaian risiko untuk melihat level risiko setiap potensi bahaya di suatu kegiatan.

Berdasarkan hasil penilaian risko diketahui bahwa level risiko rendah memiliki persentase sebesar $50 \%$ diikuti oleh level risiko ekstrim sebesar 30\%, level risiko sedang sebesar $15 \%$, dan level risiko tinggi sebesar 5\%. Hal ini dipengaruhi oleh jenis aktivitas dan bahan kimia yang digunakan di Laboratorium Pasca Cetak Polimedia. Meskipun hasil wawancara menyatakan bahwa belum pernah terjadi kecelakaan kerja secara serius, potensi kecelakaan kerja tetap ada. Salah satu bahan kimia yang masih digunakan pada proses pasca cetak adalah tiner. Komposisi tiner mengandung benzene, toluene dan xylene (BTX). Toluene mempunyai risiko bahaya tinggi yang dapat menyebabkan rusaknya organ utama yaitu susunan syaraf pusat, hati,ginjal, kulit dan lainnya. Berdasarkan hasil penelitian yang dilakukan oleh Irmasari (2018) tentang percetakan di Surabaya, diketahui bahwa kadar toluene di ruangan pasca cetak masih di bawah ambang batas karena tinta sudah mengering. Menurut Prihartini (2010) dalam Irmasari (2018) meskipun konsentrasi toluene dibawah batas normal, tetapi jika terhirup secara terus menerus dapat mempengaruhi jumlah toluen yang masuk dari bahan berbahaya tersebut. 
Tabel 2. HIRA di Laboratorium Pasca Cetak Politeknik Negeri Media Kreatif
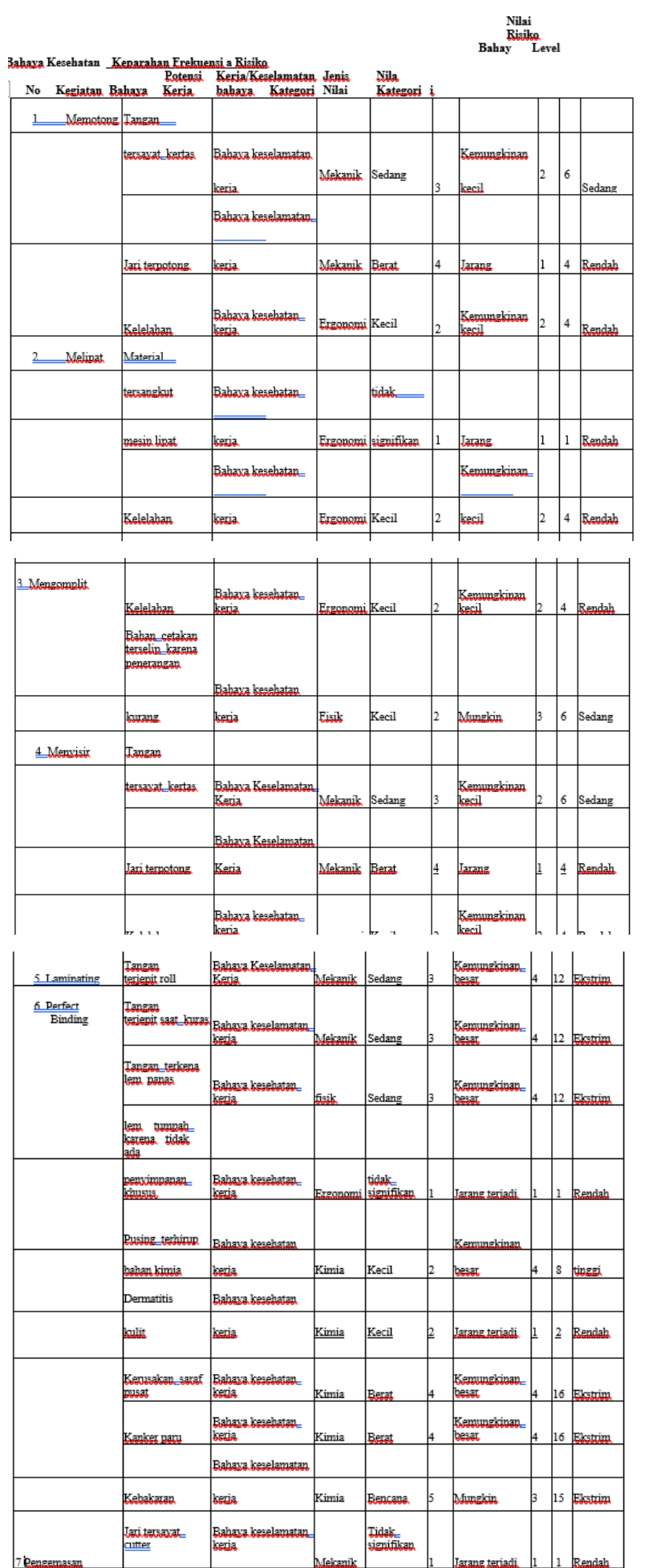

Pengendalian Bahaya dan Risiko di Laboratorium Pascacetak Politeknik Negeri Media Kreatif

Pengendalian bahaya dan risiko dilakukan berdasarkan hierarki pengendalian risiko. Berdasarkan hasil observasi penulis, beberapa sudah menerapkan pengendalian. Ruangan laboratorium sudah dilengkapi dengan ventilasi alami. Beberapa ditemukan himbauan dilarang merokok di ruangan dan tertera label pada mesin yang digunakan. Terdapat exhauts fan di atas mesin perfect binding baby poni. Pembuatan exhaust fan ini didasari oleh keluhan PLP dan teknisi karena ketika mesin dinyalakan mengeluarkan asap yang pekat. Namun, exhaust fan trersebut tidak dapat berfungsi sebagaimana mestinya. Di bagian depan laboratorium sudah terdapat APAR namun perlu dilakukan simulasi penanggulangan kebakaran. APD dan kotak P3K belum tersedia di laboratorium tersebut. SOP penggunaan APD (seperti pakaian, sarung tangan, sepatu, dan masker) dalam bekerja belum tersedia. Berikut dilampirkan data pengendalian yang dapat dilengkapi di laboratorium. 


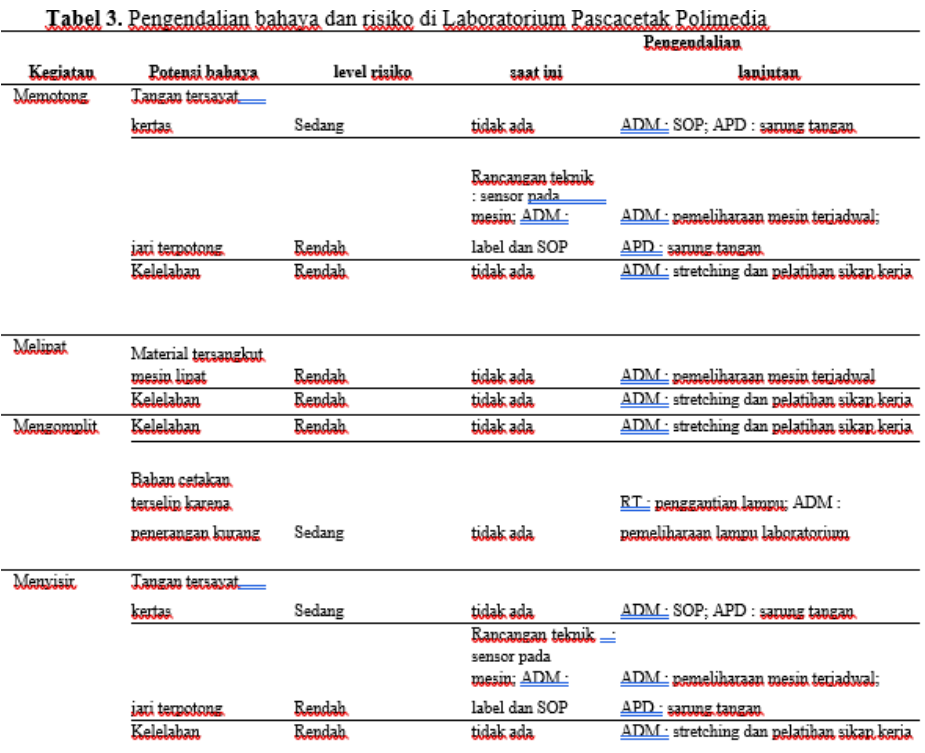

\section{KESIMPULAN}

Terdapat $\quad 7 \quad$ aktivitas di

Laboratorium Pasca Cetak Politeknik Negeri

\section{REFRENSI}

Ariani,

A. R. (2016). Hazard Identification And Risk Assessment (HIRA) sebagai Upaya Mengurnagi Risiko Kecelakaan Kerja Dan Risiko Penyakit Akibat Kerja (Pak) Di Bagian Produksi Pt

Effendi, A., Yusuf, M., \& Oesman, T. I.

(2018). Identifikasi Bahaya Kerja Dengan Hazard Identification And Risk Assesment Dan Postur Kerja Untukmengurangi Kecelakaan Kerja Pada Departemen Produksi Medari Karya Mulia. Jurnal Rekavasi, 6(2), 82-90.

Media Kreatif meliputi memotong. Melipat, Irmasari, F. 2018. Kadar Toluen di Lingkungan menyisir, laminating, perfect binding, dan pengemasan. Proses perfect binding memiliki potensi bahaya dan risiko paling banyak sebesar 8 bahaya. Berdasarkan hasil penilaian risiko diperoleh data bahwa level risiko rendah sebesar 50\%, ekstrim sebesar 30\%, sedang sebesar $15 \%$ dan tinggi sebesar $5 \%$. Level risiko ekstrim ini dipengaruhi oleh penggunaan bahan kimia di proses perfect binding. Beberapa pengendalian sudah diterapkan namun ada yang tidak berfungsi sebagaimana mestinya. Pengendalian disarankan mengikuti hierarki pengendalian bahaya. Diharapkan dengan adanya pengendalian dapat menurunkan potensi KEMNAKER RI NO $275 . \quad$ (2020). Penetapan standar kompetensi kerja nasional indonesia kategori industri pengolahan golongan pokok industri pencetakan dan reproduksi media rekaman bidang desain grafika dan produksi grafika. jakarta: Menteri KetenagaKerjaan RI. bahaya dan risiko. 
Khurniawan, A. W., Hernita, Suharto, Harmoko, F. N., Nugroho, s. A., Bakoro, A., ... Sunardi. (2020). Keselamatan Kerja di Permesinan dan Konstruksi. Jakarta: DIREKTORATSEKOLAH MENENGAH KEJURUAN.

Puspitasari, N. (2010). Hazard Identifikasi Dan Risk Assesment Dalam Upaya Mengurangi Tingkat Risiko Dibagian Produksi PT Bina Guna Kimia, Ungaran. Surakarta: UNS.

Ramadhani, F. (2017). Analisis

Kesehatan dan Keselamatan Kerja (K3) Menggunakan Metode Hazard Identification Risk Asessment And Risk Control (HIRAC). SENASSET: Universitas Serang Raya.

Roehan, K. R., Yuniar, \& Desrianty, A. (2014). K3 Menggunakan HIRA.

Tarwaka. (2008). Kesehatan dan Keselamatan Kerja Manajemen dan Implementasi K3 di tempat kerja. Surakarta: Harapan Press. 